\title{
Metabolic Engineering and Fermentation Process Strategies for L-Tryptophan Production by Escherichia coli
}

\author{
Lina Liu ${ }^{1}$, Muhammad Bilal ${ }^{1, * \mathbb{D}}$, Hongzhen Luo ${ }^{1}$, Yuping Zhao ${ }^{1}$ and Hafiz M. N. Iqbal ${ }^{2, *}$ \\ 1 School of Life Science and Food Engineering, Huaiyin Institute of Technology, Huaian 223003, China; \\ nabestwishes@126.com (L.L.); hzluo@hyit.edu.cn (H.L.); zhaoyuping@hyit.edu.cn (Y.Z.) \\ 2 School of Engineering and Sciences, Campus Monterrey, Tecnologico de Monterrey, \\ Ave. Eugenio Garza Sada 2501, Monterrey CP 64849, N.L., Mexico \\ * Correspondence: bilaluaf@hotmail.com (M.B.); hafiz.iqbal@itesm.mx (H.M.N.I.); \\ Tel.: +52-81-8358-2000 (ext. 5679) (H.M.N.I.)
}

Received: 7 March 2019; Accepted: 8 April 2019; Published: 12 April 2019

\begin{abstract}
L-tryptophan is an essential aromatic amino acid that has been widely used in medicine, food, and animal feed. Microbial biosynthesis of L-tryptophan through metabolic engineering approaches represents a sustainable, cost-effective, and environmentally friendly route compared to chemical synthesis. In particular, metabolic pathway engineering allows enhanced product titers by inactivating/blocking the competing pathways, increasing the intracellular level of essential precursors, and overexpressing rate-limiting enzymatic steps. Based on the route of the L-tryptophan biosynthesis pathway, this review presents a systematic and detailed summary of the contemporary metabolic engineering approaches employed for L-tryptophan production. In addition to the engineering of the L-tryptophan biosynthesis pathway, the metabolic engineering modification of carbon source uptake, by-product formation, key regulatory factors, and the polyhydroxybutyrate biosynthesis pathway in L-tryptophan biosynthesis are discussed. Moreover, fermentation bioprocess optimization strategies used for L-tryptophan overproduction are also delineated. Towards the end, the review is wrapped up with the concluding remarks, and future strategies are outlined for the development of a high L-tryptophan production strain.
\end{abstract}

Keywords: metabolic engineering; bioprocess; L-tryptophan; by-product; regulatory factors; polyhydroxybutyrate; fermentation process optimization

\section{Introduction}

With the development of DNA recombinant and genetic engineering technologies in microbial breeding, a large number of amino acid production strains have been constructed to achieve the industrial production of L-amino acids [1-4]. L-Tryptophan, an essential amino acid for human and animal activity, can serve as a supplement in the food and feed industry, as well as medicine to promote good sleep quality and mood [5,6]. The annual demand of L-tryptophan in the global market is above 50,000 tons, and the market growth rate is over $10 \%$ [7]. With the rapid growth of market demand, the development of L-tryptophan production technologies has received considerable research attention around the globe. Chemical synthesis, enzyme conversion, and microbial fermentation are common methods for L-tryptophan production. Given the advantages of cheap raw materials, high purity products, and the facile extraction process, microbial fermentation has currently become the method of choice for producing L-tryptophan in industry.

At present, the strains used for L-tryptophan production mainly include Escherichia coli (E. coli) and Corynebacterium glutamicum. In light of well-characterized biochemistry and physiology, favorable 
growth conditions, and the availability of versatile genetic manipulation tools, E. coli appeared as an ideal host organism for the commercial production of numerous valuable bioproducts [8]. Previously, the highest L-tryptophan yield ( $54.5 \mathrm{~g} \cdot \mathrm{L}^{-1}$ ) was achieved by E. coli AGX1757/pSC101 with a conversion rate (L-tryptophan yield on glucose) of $0.23 \mathrm{~g} \cdot \mathrm{g}^{-1}$ [9]. In E. coli, the biosynthesis pathway of L-tryptophan mainly includes the central metabolic pathway, the common aromatic amino acid pathway, and the L-tryptophan branch pathway [6]. The center metabolic pathway containing glycolysis and the pentose phosphate pathway (PPP) are responsible for the generation of phosphoenolpyruvate (PEP) and erythrose-4-phosphate (E4P) with glucose as the original substrate. The common pathway points to the process that 3-deoxy-d-arabinoheptulosonate-7-phosphate (DAHP) forms chorismate (CHA) by a series of enzyme-catalyzed reactions. The formation of DAHP is catalyzed by DAHP synthases (DS) with PEP and E4P as substrates. The L-Tryptophan branch pathway refers to the process by which $\mathrm{CHA}$ eventually generates L-tryptophan under the control of a tryptophan operon [10]. In addition to the long metabolic pathway, the complex metabolic regulation mechanism also exists in the process of the microbial biosynthesis of L-tryptophan [10]. In earlier reports, attempts at the metabolic engineering modification of L-tryptophan production strains mainly focused on eliminating feedback regulation and disrupting competing pathways in the biosynthesis routes; for example, eliminating the feedback inhibition of substrates by site-directed mutagenesis and disrupting the L-phenylalanine and L-tyrosine branch pathway to block L-phenylalanine and L-tyrosine biosynthesis, respectively [9-13]. However, the metabolic flux of the L-tryptophan biosynthesis pathway can also be influenced by several factors, such as the regulatory proteins, by-product formation, and other related biosynthesis pathways. In addition to metabolic engineering approaches (Figure 1), the fermentation optimization strategies also have significant effects on improving the L-tryptophan yield and reducing by-product formation. Based on the literature reported during the last decade and the recent advances, this review systematically describes the genetic engineering modification and fermentation optimization strategies for L-tryptophan overproduction and the factors influencing the biosynthesis of L-tryptophan.

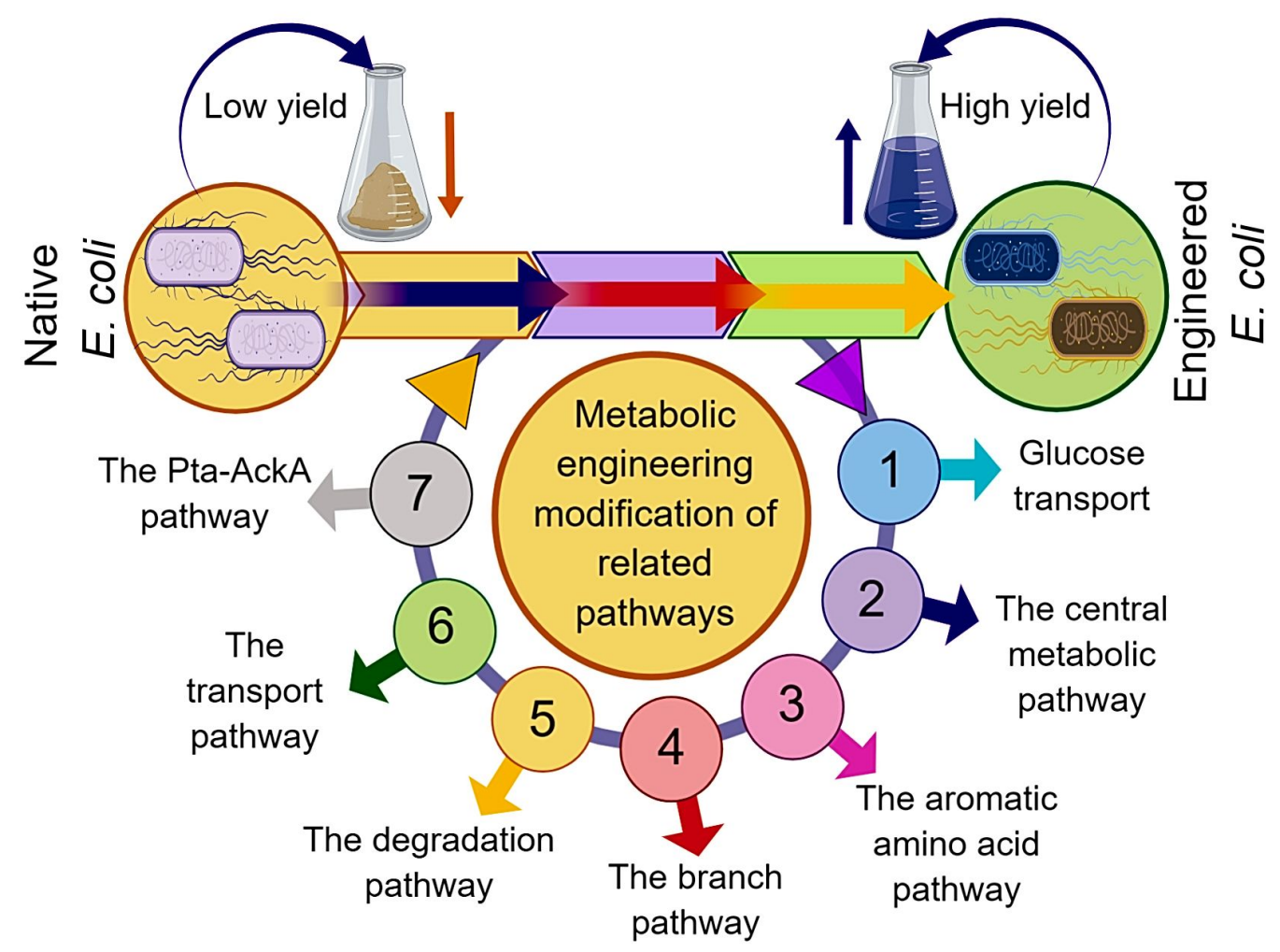

Figure 1. Schematic representation of metabolic engineering approaches for induced production of L-tryptophan using engineered E. coli. 


\section{Metabolic Engineering Modification of Related Pathways}

\subsection{Glucose Transport}

The glucose transport in E. coli is carried out by means of the phosphoenolpyruvate: the glucose phosphotransferase system (PTS) and the galactose transport system (Figure 2). In the galactose transport system, galactose permease coding by gene galP plays an important role in the transport of galactose and glucose [14]. The glucose transport efficiency of the galactose transport system is much weaker than that of PTS due to the lower expression of intracellular galp. The PTS, which is primarily responsible for glucose uptake and phosphorylation, generally includes two central phosphoryl carriers, Enzyme I (EI) and phosphoryl carrier protein (HPr) [15]. Glucose transport by PTS not only consumes large amounts of PEP, an indispensable precursor in the L-tryptophan biosynthesis pathway, but also leads to disrupting the reasonable distribution of metabolic flow between glycolysis and the tricarboxylic acid (TCA) cycle [16], resulting in a lower L-tryptophan production capacity. Therefore, the construction of PTS-deficient strains is the most common strategy used to improve the accumulation of PEP for enhanced L-tryptophan production [17-20]. Studies have shown that a positive effect of the overexpression of a glucose facilitator and glucokinase from Zymomonas mobilis could restore glucose uptake in a PTS-negative E. coli mutant [21]. Recently, an L-tryptophan production strain KW018 was constructed by the combinatorial overexpression of glucokinase and galactose permease to overcome the lower transport rate of glucose in a PTS-deficient strain [17]. In contrast to PTS knockout, a series of HPr mutants were applied in the genome for weakening PTS. As a result, the glucose transport rates of all mutant strains were relatively decreased. Among the mutant strains, E. coli FB-04(pta1) $\Delta p y k F-p t s H N 12 S$ achieved a 38.0\% increased conversion rate compared with the parent strain [22]. This phenomenon of a higher product yield upon reduced rates of sugar uptake has also been previously described [23,24].

\subsection{The Central Metabolic Pathway}

PEP and E4P, derived from glycolysis and the pentose phosphate pathway, respectively, are two critical precursors for L-tryptophan biosynthesis. Modifying the central metabolic pathway to raise the supply of PEP and E4P increased the carbon flow in the L-tryptophan biosynthesis pathway, and thus, finally improved the L-tryptophan titer. The biosynthesis of E4P is mainly catalyzed by transketolase (TKT), an isozyme encoded by the genes $t k t A$ and $t k t B$, in which the $t k t A$-encoded isozyme plays a major role. To increase E4P supply, transketolase was generally overexpressed in an L-tryptophan production strain. Overexpressing transketolase together with AroG and the tryptophan operon in an L-tryptophan production strain led to an increase in the L-tryptophan yield of $90 \%$ [25]. Previously, L-tryptophan production strain GPT1002 was constructed by overexpressing genes $t k t A$, mutated trpE, and $\operatorname{aroG}[20]$.

Considering that pyruvate kinase, encoded by genes $p y k A$ and $p y k F$, catalyzes PEP to generate pyruvate (PYR), pyruvate kinase deficiency improved the accumulation of PEP [26]. It was reported that gene $p y k F$ deletion significantly raised the expression of related enzymes in the aromatic amino acid common pathway $[27,28]$. In contrary to pyruvate kinase, phosphoenolpyruvate (PEP) synthetase (encoding by gene $p p s A$ ) catalyzes the conversion of PYR into PEP, contributing to the accumulation of PEP [29]. Overexpressing PPSA enhanced the level of PEP; in turn, the content of DAHP in the aromatic amino acid common pathway was increased [30]. Genes of $p p s A$ and $t k t A$ combined with aroG and $\operatorname{trp} E D$ were reported to be overexpressed for the development of a L-tryptophan production strain [31]. In addition, the inactivation of PEP carboxylase (PEPC), an enzyme catalyzing the formation of oxaloacetate from PEP, was found to be beneficial for the accumulation of PEP [32]. 


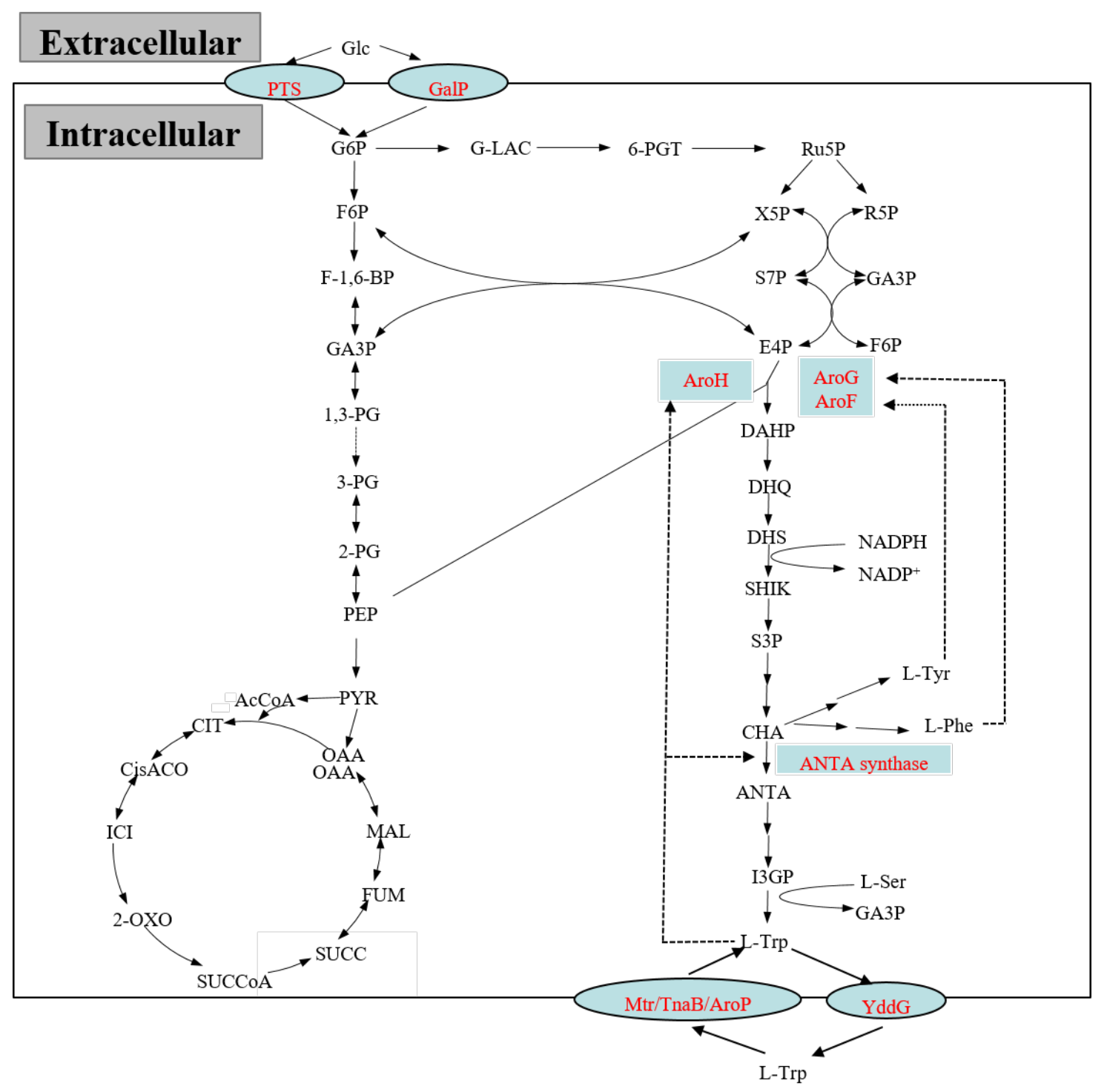

Figure 2. The metabolic pathway involved in L-tryptophan biosynthesis and its regulations in E. coli. The dashed lines indicate feedback inhibitions by the aromatic amino acid end products.

\subsection{The Aromatic Amino Acid Common Pathway and the L-tryptophan Branch Pathway}

In the biosynthesis pathway of L-tryptophan, the aromatic amino acid common pathway and the L-tryptophan branch pathway involved the feedback inhibitions of a series of rate-limiting enzymes, mainly including DAHP synthase and ANTA synthase [10]. DAHP synthase, a main rate-limiting enzyme catalyzing PEP and E4P to form DAHP, plays a key role in directing carbon flow from the central metabolic pathway to the common pathway. In E. coli, DAHP synthase is composed of three isozymes: AroG, AroF, and AroH, whose activities are feedback-inhibited by L-phenylalanine, L-tyrosine, and L-tryptophan, respectively. Given that the activities of AroG and AroF account for more than $99 \%$ of total enzyme activities, significant research work has been dedicated to screening out anti-feedback regulated isozymes of AroG and AroF to eliminate the feedback inhibition by substrates [10]. For AroG, two AroG mutants, P150L and D146N, completely relieved the feedback inhibition by L-phenylalanine [33]. For AroF, studies have indicated that AroF mutants (N8K, P148L, and Q152I) could remove the feedback regulation by L-tyrosine [34,35]. Moreover, deleting the Ile11 residue of AroF also achieved a significant effect of anti-feedback inhibition, and this mutant was employed in the construction of an L-tryptophan production strain [10]. ANTA synthase, another major rate-limiting enzyme encoded by the gene $\operatorname{trpED}$, catalyzes the generation of ANTA from 
CHA, whereas the activity of ANTA synthase is inhibited by L-tryptophan [36]. The problem of the feedback inhibition of ANTA synthase was completely addressed by replacing the 40-serine residue with phenylalanine in the enzyme TrpE [37], and a higher L-tryptophan yield was obtained compared to that of the parent strain by overexpressing the mutated enzyme [10]. Except for the discovery of anti-feedback regulatory enzymes, overexpression of enzymes related to the common pathway and the L-tryptophan branch pathway also plays a decisive role in the overproduction of L-tryptophan. In the L-tryptophan branch pathway, the structural genes, known as the tryptophan operon in the genome, are responsible for L-tryptophan biosynthesis [17], whereas the attenuator, a segment nucleotide sequence consisting of 162 nucleotides located before the structural genes, regulates the tryptophan operator. When intracellular L-tryptophan reaches a certain level, the secondary structure conformation of the attenuator changes, and then prevents the transcription of the tryptophan operon [38]. It was reported that a tryptophan attenuator-deficient strain exhibited a higher transcription of tryptophan operon genes than that of the parent strain GPT1001 [20]. In order to improve the expression of the structural genes, a low-copy plasmid containing the tryptophan operon (including anti-feedback inhibited TrpE) was introduced to an L-tryptophan production strain, and ANTA was added to the fermentation medium at the same time, resulting in an accumulation of L-tryptophan of $6.2 \mathrm{~g} \cdot \mathrm{L}^{-1}$ [11]. Li et al. [37] overexpressed the anti-feedback inhibited enzymes of AroG and TrpED for L-tryptophan biosynthesis, leading to an L-tryptophan yield of $0.168 \mathrm{~g} \cdot \mathrm{L}^{-1}$ in the shake flask fermentation. Zhao et al. [10] employed the method of overexpressing anti-feedback-inhibited AroF and the tryptophan operator in a low-copy vector pSV for the development of L-tryptophan production strain FB-04. Moreover, considering that L-serine is a crucial terminal substrate in the L-tryptophan biosynthesis pathway, the increased level of L-serine is required for efficient L-tryptophan production. It is well-known that 3-phosphoglycerate dehydrogenase SerA encoded by the gene serA plays an important role in the biosynthesis of L-serine [39]. Overexpression of the gene serA was evidenced to have an obvious effect on L-tryptophan overproduction [6]. Accompanied by fermentation optimization, overexpressing anti-feedback-inhibited AroG, the whole tryptophan operator, and ser $A$ in a constitutive plasmid and then introducing this plasmid into the host eventually obtained an L-tryptophan yield up to $42 \mathrm{~g} \cdot \mathrm{L}^{-1}$ [40].

\subsection{The Branch Pathway}

The biosynthesis of L-tryptophan is usually accompanied by the generation of a small amount of the other two aromatic amino acids (L-phenylalanine and L-tyrosine). The biosynthesis pathways of L-phenylalanine and L-tyrosine can be blocked to prevent the loss of carbons towards these pathways. For example, inactivation of PheA, a bi-functional enzyme of the L-phenylalanine branch [41], had a significant influence on L-tryptophan biosynthesis, causing an improvement of the L-tryptophan yield by 1.38-fold. Inactivation of TyrA, an enzyme of the L-tyrosine branch, results in the completely blocked biosynthesis of L-phenylalanine and L-tyrosine. However, deficiencies of both L-phenylalanine and L-tyrosine might affect the growth of cells [10].

\subsection{The Degradation Pathway}

In microbial strains, the biosynthesis of L-tryptophan is always regulated by the degradation of L-tryptophan. The tryptophanase TnaA encoded by the tnaA gene plays a significant role in L-tryptophan degradation [42]. TnaA catalyzes the formation of L-tryptophan in the presence of a high concentration of ammonia and PYR; however, it only has an effect on degrading L-tryptophan in the normal physiological state of cells. Thus, inactivation of TnaA was confirmed to facilitate the biosynthesis of L-tryptophan [11,43]. Moreover, inactivation of TnaA was implemented for constructing FB-02, an L-tryptophan production strain, leading to a raised L-tryptophan yield by 2.7-fold [10]. 


\subsection{The Transport Pathway}

The L-tryptophan transport system, including the three permeases Mtr, TnaB, and AroP, is engaged in the uptake of L-tryptophan in E. coli. Among them, Mtr and TnaB display a high-affinity and low-affinity uptake specific to L-tryptophan, respectively, while AroP participates in the transfer of all aromatic amino acids [6]. Single deficiency of Mtr, TnaB, and AroP, led to a lower L-tryptophan absorption activity and a significantly higher accumulation of extracellular L-tryptophan. Among all knockout mutants, the absence of Mtr achieved the highest L-tryptophan yield, increasing by $34 \%$ compared to the parent strain [44]. A higher growth rate in the logarithmic growth period has also been observed by AroP inactivation, and the final L-tryptophan yield of the mutant increased by $13.3 \%$ in a 30-L fed-batch fermentation process [42]. Also, the concerted inactivation of Mtr, TnaB, and AroP was reported to enhance L-tryptophan production by $51.6 \%$ compared to the parent strain [45]. Apart from these three permeases described above, YddG, an aromatic amino acid exporter, showed remarkable facilitation for L-tryptophan transport and overproduction [46,47]. Studies have demonstrated that the overexpression of YddG in Mtr-deficient strains accumulated a lower intracellular L-tryptophan content, but higher extracellular L-tryptophan yield [48]. Moreover, the increased level of YddG expression by fusing with promoter Ptac had an obvious promotion for L-tryptophan biosynthesis, raising the L-tryptophan yield by $14.3 \%$ compared to that of the parent strain [47].

\subsection{The Pta-AckA Pathway}

In the process of L-tryptophan fermentation using glucose as a carbon source, the rapid growth of cells and lower level of dissolved oxygen often lead to the accumulation of acetate, which not only wastes the carbon source and reduces the conversion rate, but also inhibits the growth of cells and L-tryptophan biosynthesis [49]. When the concentration of acetate reaches a certain level, cell growth and L-tryptophan biosynthesis can be inhibited [50]. Therefore, reducing the formation of acetate has a significant effect on the overproduction of L-tryptophan. To minimize acetate formation in the fermentation process as much as possible, the dissolved oxygen must be sufficient. However, this mainly increases the production cost in industrial production. Thus, genetic engineering would be a convenient method to reduce acetate formation. In E. coli, both, the PoxB oxidase pathway and the Pta-AckA pathway are involved in acetate formation, in which the latter is the primary acetate formation pathway (Figure 3) [51]. Pyruvate oxidase is not only a stationary-phase enzyme, and the removal of the poxB gene affects the central metabolism at the enzyme level in E. coli, leading to a reduced glucose uptake rate and cell growth rate [52]. In the Pta-AckA pathway, the two enzymes phosphate acetyltransferase (Pta) and acetate kinase (AckA) catalyze the formation of acetate from acetyl-CoA, successively. Pta, the key enzyme in this pathway, catalyzes the conversion of acetyl-CoA to acetyl phosphate [53]. Despite that, the AckA-deficient strain displayed better fermentative properties, displaying a $21.8 \%$ reduction in acetate content and a $6.5 \%$ increase in L-tryptophan production compared with the parental strain [54]. Pta-AckA pathway disruption by the inactivation of Pta is the most common genetic manipulation employed to reduce acetate accumulation $[55,56]$. It was reported that Pta was inactivated in the construction of L-tryptophan production strain TRTH 0709/pMEL03, largely decreasing acetate formation [48]. Given that the Pta-AckA pathway is closely related to physiological metabolism and acetyl phosphate plays an important cellular role as a phosphorus donor in the effect of acetylation, the absence of Pta caused a remarkable reduction in cell growth [57]. In contrary to the disruption of the Pta-AckA pathway, a weakened Pta-AckA pathway was employed, resulting in a $15.5 \%$ increase in the L-tryptophan yield and a decrease in acetate content (only $48 \%$ of the control). The decreased Pta-AckA pathway was also confirmed to enhance the metabolic flow of the L-tryptophan biosynthesis pathway [49]. 


\section{Glucose}

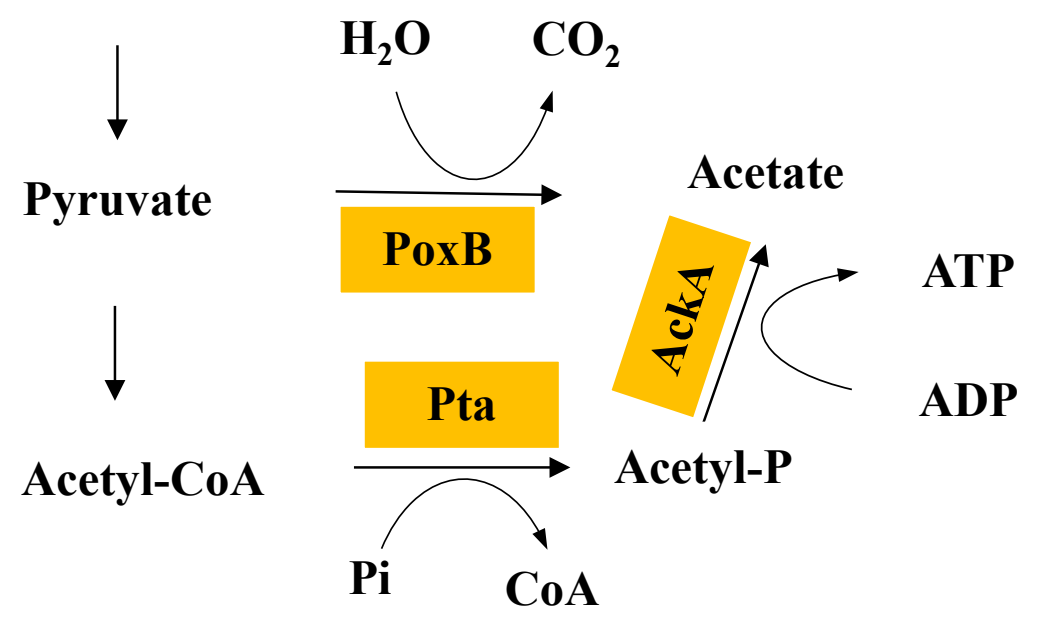

Figure 3. The acetate biosynthesis pathway in E. coli.

\subsection{The Polyhydroxybutyrate Synthesis Pathway}

In the process of L-tryptophan biosynthesis by E. coli, some particular substances can improve L-tryptophan biosynthesis by regulating carbon metabolism. Polyhydroxybutyrate (PHB), a biopolymer accumulated under a carbon surplus condition, can not only enhance the stress resistance of the host, but also change the metabolic flow of E. coli [58]. Poly(3-hydroxyalkanoate) polymerase, encoded by the genes $p h a A$, phaB, and $p h a C$, catalyzes the formation of PHB from acetyl-CoA, successively (Figure 4). Previously, improved succinate production and decreased reduced acetate secretion were achieved by employing the PHB biosynthesis pathway in succinate production strains [58]. Besides, the construction of the PHB biosynthesis pathway in GPT1002 was reported to direct acetyl-CoA to PHB biosynthesis, resulting in an improvement in L-tryptophan production and a reduction in acetate secretion [19].

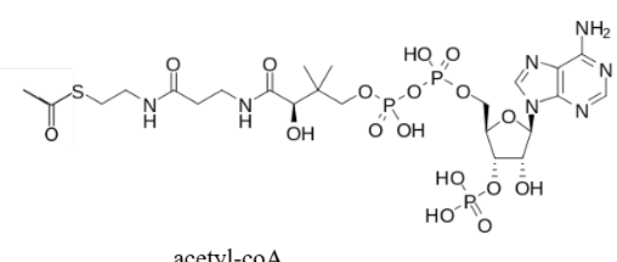

acetyl-coA

\section{phaA}

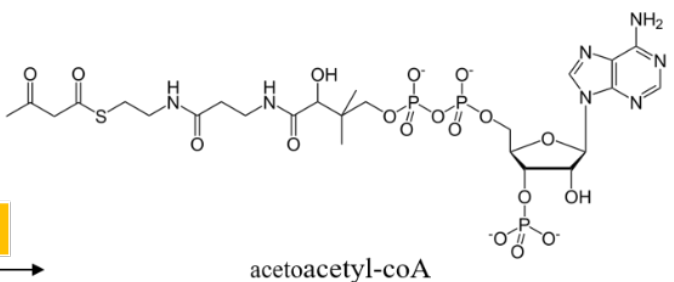

acetoacetyl-coA

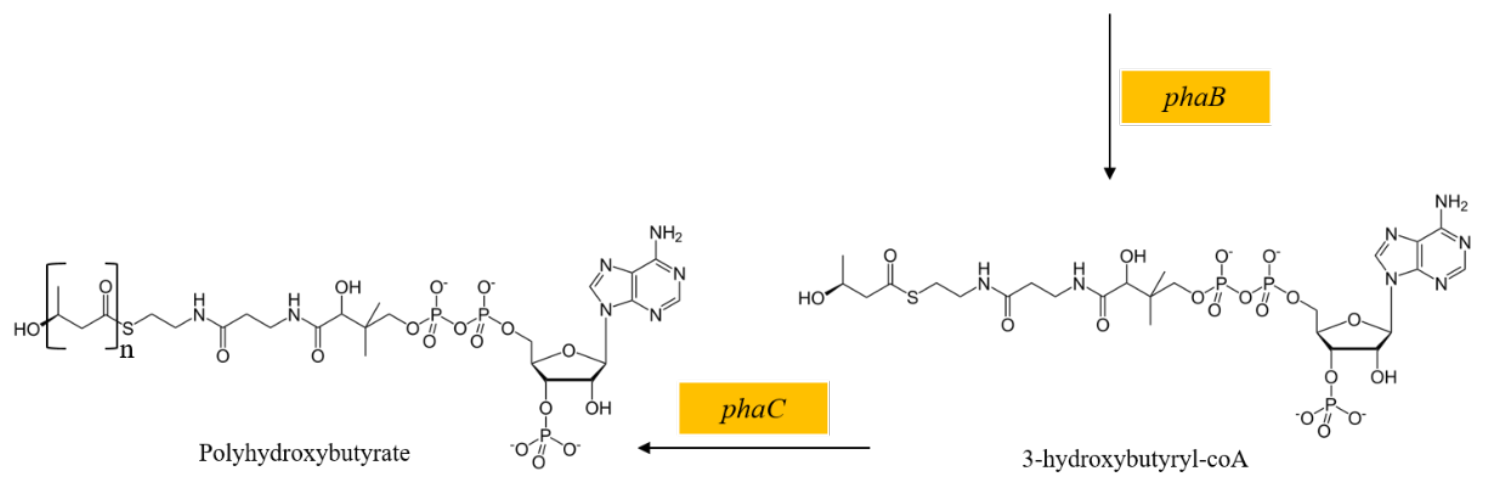

Figure 4. The PHB biosynthesis pathway. 


\section{Transcriptional Regulation by Regulatory Factors}

The regulatory network of L-tryptophan biosynthesis is complex, which involves the expression of various genes [10]. The transcriptional regulation itself involving a complex network of global and regulatory factors has a considerable influence on gene expression, which in turn, can affect the distribution of metabolic fluxes in E. coli [59]. The results of L-tryptophan metabolism network optimization indicated that the relative weakened metabolic flow of the TCA cycle and enhanced metabolic flow of the pentose phosphate pathway were beneficial for increasing the metabolic flow of the L-tryptophan biosynthesis pathway [60]. Global regulator protein Cra (renamed from FruR) is well-known to affect the metabolic flow of the central metabolic pathway by regulating the transcription of genes involved in carbon metabolism and energy metabolism [61]. Inactivating Cra can upregulate the expression of genes involved in the pentose phosphate pathway and downregulate the expression of genes involved in the TCA cycle (Figure 5) [62,63]. The upregulated metabolic flow of the pentose phosphate pathway can improve the supply of NADPH, a critical cofactor involved in L-tryptophan biosynthesis [10]. Inactivation of Cra enhanced the metabolic flow of the L-tryptophan biosynthesis pathway, leading to an increased L-tryptophan yield and conversion rate of $62.5 \%$ and $52.4 \%$, respectively [64]. Global regulator CsrA, as a carbon storage regulator, participates in the regulation of metabolic flow. It was found that the absence of CsrA could enhance the metabolic flow of gluconeogenesis, contributing to the accumulation of PEP [65]. Silencing CsrA by artificial sRNAs has a significant promoting effect on L-tyrosine biosynthesis, thus improving L-tyrosine yield by 1.2-fold compared to the parent strain [66]. CsrB, a small untranslated RNA from the carbon storage regulator, was overexpressed in E. coli KT1306 to improve the availability of PEP, resulting in an obvious increase in the L-tryptophan yield of 7.5\% [66]. Except for the global regulator mentioned above, the special regulator TyrR has a negative role in L-tryptophan biosynthesis, because this TyrR inhibits the transcription of genes involved in aromatic amino acid biosynthesis, containing the gene encoding DAHP synthase, a critical enzyme in the L-tryptophan biosynthesis pathway [67]. Researches have pointed out that inactivating TyrR resulted in a remarkable increase of DAHP synthase activity [68]. It is well-known that TrpR, a repressor encoded by a $\operatorname{trpR}$ gene located upstream of the tryptophan operator, regulates the transcription and translation of the tryptophan operator [69]. When the content of L-tryptophan in cells reaches a particular value, the transcription of the operator is stopped due to the inhibition of the repressor TrpR. Studies have shown that the development of L-tryptophan production strains is always accompanied by the inactivation of $\operatorname{TrpR}[10,11]$. Attenuation is another special type of regulatory mechanism in the biosynthesis of tryptophan, which is achieved by the leader region trpL situated upstream of the trpEDCBA genes [70]. Briefly, two tryptophan codons are adjacently present in the trpL region, thus making translation sensitive to the intracellular L-tryptophan level. At a high L-tryptophan level, the ribosomes do not stall at this point, leading to the formation of the termination structure of the mRNA. However, when the L-tryptophan level is inadequate, the RNA polymerase stalls at the position of the two adjacent tryptophan codons, and prevents the formation of the transcription termination structure, and transcription of the trpEDCBA operon continues [71]. 


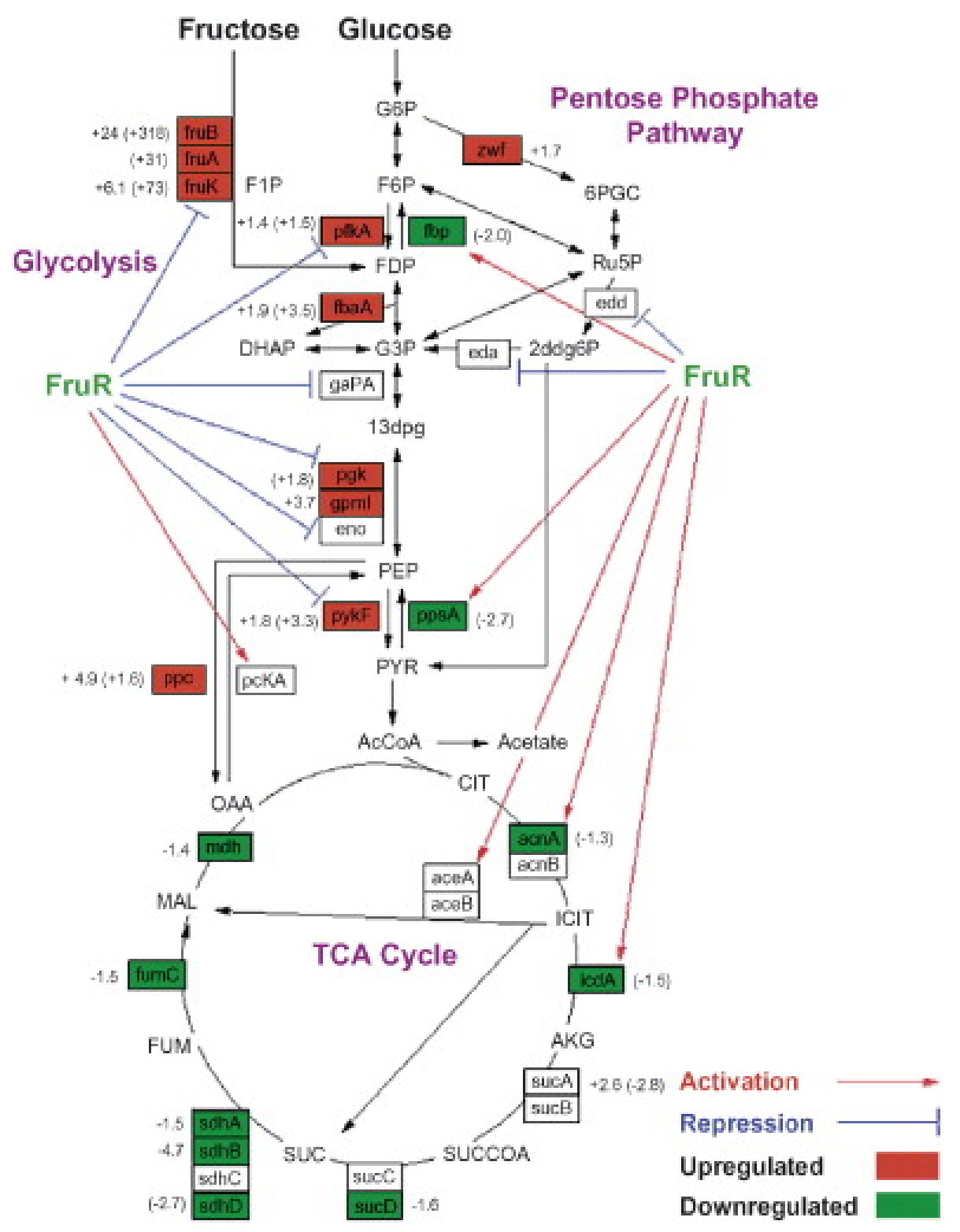

Figure 5. Combined overview of FruR-regulated genes and overall gene expression changes in the central metabolic pathways. The three major central metabolic pathways shown are glycolysis, the pentose phosphate pathway, and the TCA cycle. Values without brackets are protein expression fold changes of P+ fruR cells over P+ WT cells, while values in brackets are the corresponding transcriptional fold changes. Genes that are activated by FruR $(\rightarrow)$ are generally downregulated (green boxes), while those that are repressed by FruR $(-)$ are generally upregulated (red boxes) in $\mathrm{P}+$ fruR cells vs. P+ WT cells. At least two biological samples, each with three technical replicates, were analyzed. Reprinted from Ow et al. [62], with permission from Elsevier. Copyright (2007) Elsevier B.V.

\section{Fermentation Process Strategies}

\subsection{Optimization of Fermentation Conditions}

Microbial fermentation of L-tryptophan production by $E$. coli has been widely studied. Optimization of the glucose feeding rate had an apparent stimulating effect on the L-tryptophan yield [72,73]. It has been demonstrated that the L-tryptophan yield and conversion rate were increased by $35 \%$ and $38 \%$, respectively, by optimizing the glucose supplementation rate in a $14-\mathrm{L}$ 
fermenter [40]. Given the inhibition of acetate for L-tryptophan production, the methods of maintaining the dissolved oxygen level, determining the appropriate initial glucose concentration, limiting glucose flow, and controlling the specific growth rate were performed to reduce the production of acetate in a 5 -L fermenter [74]. Optimization results showed that acetate formation was decreased by $51 \%$, thereby resulting in a higher cell biomass and L-tryptophan yield by $51 \%$ and $47 \%$ compared to that of the parent strain, respectively, in the process of high-density fermentation. In addition, the effects of a specific growth rate and inorganic salt on L-tryptophan production by the fermentation of recombinant $E$. coli $\mathrm{FB}-04$ were investigated to reduce the acetate formation. The results indicated that an appropriate specific growth rate and inorganic salt concentration led to a lower acetate accumulation, and finally, a higher L-tryptophan yield $\left(53.4 \mathrm{~g} \cdot \mathrm{L}^{-1}\right)$ was obtained in a 3-L fermenter, increasing by $141.6 \%$ compared to the conditions without optimization. Furthermore, the L-tryptophan yield of FB-04 reached $53.6 \mathrm{~g} \cdot \mathrm{L}^{-1}$ by scale-up production in a 30-L fermenter [75]. Moreover, given that the $\mathrm{pH}$ in medium affects the production of L-tryptophan, a three-stage strategy was employed to control the $\mathrm{pH}$, resulting in an optimum yield of $43.65 \mathrm{~g} \cdot \mathrm{L}^{-1}$ by E. coli TRJH/DPB in a 5 -L seed fermenter [76]. Except for the fermentation factors mentioned above, temperature also had a noticeable effect on $\mathrm{L}$-tryptophan production. A Variable-temperature and Control System $\left(30-36^{\circ} \mathrm{C}\right.$ sequential heating process) was achieved for E. coli strain TRTH fed-batch fermentation in a 5-L fermenter, leading to a $15 \%$ higher L-tryptophan yield compared to the single temperature control strategy [77]. Table 1 portrays the recent metabolic engineering and fermentation optimization strategies for enhanced L-tryptophan production by E. coli from glucose.

\subsection{Addition of Related Substances}

Previously, Aiba et al. [11] introduced a low-copy plasmid expressing the enzymes of anti-feedback inhibited TrpD, $\operatorname{TrpE}$ into a $\operatorname{trp} R$, and tnaA double deletion strain for the development of a L-tryptophan production strain. To further raise the L-tryptophan yield, anthranilate (ANTA) was incorporated into the fermentation medium, leading to an accumulation of L-tryptophan of $6.2 \mathrm{~g} \cdot \mathrm{L}^{-1}$ [11]. On this basis, combining chemical mutagenesis with the addition of a surfactant in the fermentation medium, the final L-tryptophan yield was as high as $54.5 \mathrm{~g} \cdot \mathrm{L}^{-1}$ [9]. Given that xylose forms E4P catalyzed by a series of enzymes [46], adding xylose into the medium as a co-substrate was found to enhance the precursor E4P supply for L-tryptophan production [19]. Indole and L-serine are well-known substrates for L-tryptophan biosynthesis in microbial processes [10]. Similarly, the supplementation of Iranian cane molasses, an inexpensive L-serine source, and adding Triton X-100 into the medium as an indole reservoir, improved the biosynthesis of L-tryptophan [79]. In addition, adding PL61 was known to have a significant effect on improving L-tryptophan production, leading to the highest titer $\left(35.5 \mathrm{~g} \cdot \mathrm{L}^{-1}\right)$ of the L-tryptophan yield in a 10-L fermenter [73]. It was reported that glutamate, a by-product during L-tryptophan biosynthesis, accumulated to an extremely high level, whereas the content of glutamine, a crucial substrate, was maintained at a relatively low level $[40,78]$. Thus, overexpressing glutamine synthetase, which catalyzes glutamate to form glutamine, might be an important measure to further improve the L-tryptophan production titer. 
Table 1. Metabolic engineering and fermentation optimization strategies for L-tryptophan production by E. coli from glucose.

\begin{tabular}{|c|c|c|c|c|c|c|c|c|}
\hline Strains & Gene Modification $^{\mathrm{a}}$ & $\begin{array}{c}\text { Optimization } \\
\text { Strategies }\end{array}$ & $\begin{array}{c}\text { Fermentative } \\
\text { Scale (L) }\end{array}$ & $\begin{array}{l}\text { L-Tryptophan } \\
\text { Yield }\left(\mathrm{g} \cdot \mathrm{L}^{-1}\right)\end{array}$ & $\begin{array}{l}\text { Conversion } \\
\text { Rate }\left(g^{-1} \cdot{ }^{-1}\right) \\
\end{array}$ & $\begin{array}{l}\text { Productivity } \\
\left(\mathrm{g} \cdot \mathrm{L}^{-1} \mathrm{~h}^{-1}\right)\end{array}$ & $\begin{array}{c}\text { Acetate } \\
\text { Content }\left(\mathrm{g} \cdot \mathrm{L}^{-1}\right) \\
\end{array}$ & Reference \\
\hline KW023 & $\begin{array}{l}\text { A: } \operatorname{trpEDCBA}, \text { aroG fbr }, \text { galP, galk } \\
\text { B: pykF, ptsH, trpR, attenuator } \\
\text { C: downregulation of } p t a\end{array}$ & - & 5 & 39.7 & 0.167 & 1.6 & 0.5 & [17] \\
\hline S028 & 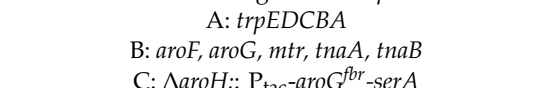 & - & 1.5 & 40 & 0.15 & 0.6 & - & [78] \\
\hline$\Delta p y k F-p t s H N 12 S$ & $\begin{array}{c}\text { A: aroFfbr } \text { trpE }^{f b r} D \\
\text { B: trpR, tnaA, phe } A, \text { tyrA, pykF } \\
\text { C: } \Delta \text { pta1:: pta1, } \Delta \text { ptsH:: ptsHN12S }\end{array}$ & - & 3 & 26 & 0.178 & - & 0.6 & [22] \\
\hline FB-04(pta1) & $\begin{array}{l}\text { A: aroffor, } \operatorname{trp} E^{f b r} D \\
\text { B: trpR, tnaA, pheA, tyrA, } \\
\text { C: } \Delta \text { pta:: pta1, }\end{array}$ & - & 3 & 44 & 0.129 & 0.82 & 2.1 & [49] \\
\hline ATCC 11303 & & $\begin{array}{c}\text { Iranian cane molasses } \\
\text { concentration } \\
\text { Triton X-100 concentration }\end{array}$ & 10 & 0.43 & - & - & - & [79] \\
\hline Dpta/mtr-Y & $\begin{array}{c}\text { A: } \operatorname{aro} G^{f b r}, \operatorname{trp} E^{f b r} D C B A, \operatorname{ser} A, t k t A, p p s A, y d d G \\
\text { B: } \operatorname{trpR}, \operatorname{tna} A, p t a, \operatorname{tyr} A, \text { mtr }\end{array}$ & - & 30 & 48.7 & 0.219 & - & 0.95 & [19] \\
\hline GPT1017 & $\begin{array}{l}\text { A: } a r G^{f b r}, \operatorname{trp} f^{f b r}, t k t A \\
\text { B: trpR, tnaA, tnaB, } p t s H, \text { tyrA, aroP, } m \text { tr attenuator } \\
\text { C: } \Delta \text { trp promoter: } 5 \mathrm{CP}_{\text {tacs }} \text { promoter cluster }\end{array}$ & - & 5 & 16.3 & - & 0.25 & 1.02 & [45] \\
\hline W3110-ZDrr & $\begin{array}{l}\text { A: } \operatorname{trp} E D C B A \\
\text { B: } \operatorname{trpR}, \operatorname{tna} A\end{array}$ & $\begin{array}{l}\text { Glucose feeding rate } \\
\text { PL61 concentration }\end{array}$ & 10 & 35.5 & - & - & - & [73] \\
\hline $\mathrm{TRJH} / \Delta \mathrm{PB}$ & $\begin{array}{l}\text { A: } \operatorname{trpEDCBA} \\
\text { B: } \operatorname{trpR}, \operatorname{tnaA}, p t a\end{array}$ & $\begin{array}{c}\mathrm{pH} \\
\text { Glucose Feeding rate }\end{array}$ & 30 & 43.7 & - & - & 1.15 & [76] \\
\hline FB-04/pSV-04 & - & $\begin{array}{l}\text { Specific growth rate } \\
\text { Salt ion concentration }\end{array}$ & 3 & 53.4 & - & - & 0.3 & [75] \\
\hline TRJH & A: $\operatorname{trp} E D C B A$ & Glucose feeding rate & 30 & 38.8 & 0.199 & - & 0.9 & [72] \\
\hline FB-04/pSV03 & $\begin{array}{c}\text { A: } \operatorname{aroF}, \operatorname{trp} E D \\
\text { B: } \operatorname{trpR}, \operatorname{tna} A, m t r, p h e A\end{array}$ & - & 3 & 14.7 & 0.12 & 0.05 & - & [44] \\
\hline TRTH-Y & $\begin{array}{l}\text { A: } \operatorname{trpEDCBA}, y d d G \\
\text { B: } \operatorname{tnaA}\end{array}$ & - & 30 & 36.3 & - & 1.01 & - & [16] \\
\hline TRTH/pSV-709 & A: $\operatorname{trpEDCBA}$ & $\begin{array}{l}\text { Dissolved oxygen level } \\
\text { Initial glucose concentration } \\
\text { Glucose feeding rate } \\
\text { Specific growth rate }\end{array}$ & 5 & 33.9 & - & - & 0.9 & [74] \\
\hline TRTH/pSV-709 & A: $\operatorname{trp} E D C B A$ & Temperature & 5 & 30.2 & - & - & - & [77] \\
\hline JB102 & A: $\operatorname{aro} G^{f b r}, \operatorname{trp} E^{f b r}, \operatorname{ser} A$ & Glucose feeding rate & 14 & 42.3 & 0.176 & - & - & [40] \\
\hline AGX1757/pSC101 & $\begin{array}{l}\text { A: } \operatorname{trp} E^{f b r} D \\
\text { B: } \operatorname{trpR}, \operatorname{tna} A\end{array}$ & ANTA concentration & 11 & 54.5 & 0.23 & 0.683 & - & [9] \\
\hline EMS4-C25/pTC701 & A: $\operatorname{trpEDCBA}$ & - & Shake flask & 9.2 & 0.13 & & - & [13] \\
\hline
\end{tabular}

A: gene overexpression; B: gene deletion; C: other genome modification. " - " indicates no description. 


\section{Conclusions and Future Prospects}

Nowadays, the market demand for L-tryptophan is increasing rapidly. Given the advantages of cheap raw materials, high purity products, and the easy extraction process, the fermentative production of L-tryptophan by genetically engineered microbial strains has received considerable attention in the industry. In the wild-type strain, to satisfy the normal physiological function of cells, only a small number of intermediates from the center metabolic pathway can be used for L-tryptophan biosynthesis by following the economics principle. Metabolic engineering modification for L-tryptophan production by $E$. coli is an excellent example of the sustainable production of a highly valued product. With the development of metabolic engineering breeding, a large number of L-tryptophan production strains have been constructed. Increasing the expression of enzymes involved in L-tryptophan biosynthesis is well-known to have a significant effect on L-tryptophan production. Given the limited capacity of a plasmid to accommodate genes, overexpression of a series of enzymes involved in L-tryptophan biosynthesis in the plasmid is restricted; therefore, it is an excellent way to improve the expression of key enzymes by genome modification. Given the complexity of L-tryptophan biosynthesis to achieve a significant increase of L-tryptophan production, the expression of the enzymes needs combinatorial modulation by employing promoters with different start-up strengths. Previously, a promoter library including promoters with different start-up strengths was first constructed, and then combinatorial modulation of the genes galP and glk was obtained by applying the promoter library to the E. coli genome for enhancing alternative glucose utilization [80]. Thus, the promoter library mentioned above is expected to apply in the construction of L-tryptophan production strains, coordinating regulation of the expression of genes related to L-tryptophan biosynthesis in the genome.

In addition to increasing the expression of the enzymes, the transcriptional regulation itself involves a complex network of global and specific regulators, and is generally considered the main role in gene expression involved in L-tryptophan biosynthesis, in turn, controlling the distribution of metabolic fluxes [59]. The global regulatory protein (Crp) is well-known to enhance the metabolic flow of the tricarboxylic acid cycle (TCA) by upregulating the expression of enzymes related in the TCA cycle [81]. Thus, inactivation of Crp is expected to weaken the metabolic flow of the TCA cycle, which is beneficial for L-tryptophan production. Moreover, FlhD, a regulatory protein involved in flagella synthesis, is a transcriptional regulatory factor involved in aerobic respiration. Inactivation of FlhD enhanced aerobic respiration and weakened anaerobic respiration [82], contributing to the reduction of acetate formation in the case of an insufficient oxygen supply [50]. Except for metabolic engineering modification for L-tryptophan production, various large-scale analytical techniques, such as proteome and transcriptome analysis, are expected to facilitate the further efficient development of L-tryptophan production strains.

Author Contributions: Conceptualization, L.L., M.B., and H.L.; Literature review, L.L. and H.L.; Writing-Original Draft Preparation, L.L., M.B., and H.L.; Figures, M.B. and H.M.N.I.; Tables, M.B.; Writing-Review \& Editing, L.L., M.B., and H.L.; Revisions \& Final editing, M.B. and H.M.N.I.; and APC Funding Acquisition, H.M.N.I.

Funding: This research received no external funding. The APC (ID: processes-469951) was funded by MDPI, St. Alban-Anlage 66, 4052 Basel, Switzerland.

Acknowledgments: This study was funded by financial support from the Natural Science Foundation of Jiangsu Province (BK20170459), China; the National Natural Science Foundation of China (21808075); and the Research and Innovation Project for College Graduates of Jiangsu Province (no. KYLX15-1143). All authors are grateful to their representative institutes for providing literature facilities.

Conflicts of Interest: The authors report no conflicting interest in any capacity, competitive or financial. 


\section{Abbreviations}

$\begin{array}{ll}\text { GLC } & \text { glucose } \\ \text { G6P } & \text { glucose-6-phosphate } \\ \text { F6P } & \text { fructose-6-phosphate } \\ \text { F-1,6-BP } & \text { fructose-1, 6-bisphosphate } \\ \text { GA3P } & \text { glyceraldehyde 3-phosphate } \\ \text { PG } & \text { phosphoglycerate } \\ \text { PEP } & \text { phosphoenolpyruvate } \\ \text { PYR } & \text { pyruvate } \\ \text { AcCoA } & \text { acetyl coenzyme A } \\ \text { CisACO } & \text { cis-aconitate } \\ \text { OAA } & \text { oxaloacetate } \\ \text { CIT } & \text { citric acid } \\ \text { ICI } & \text { iso-citric acid } \\ \text { MAL } & \text { malate } \\ \text { SUCC } & \text { succinate } \\ \text { SUCCoA } & \text { Succinate coenzyme A } \\ \text { 2-OXO } & \text { 2-oxoglutarate } \\ \text { FUM } & \text { fumarate; } \\ \text { G-LAC } & \text { 6-phospho-glucono-1, 5-lactone; } \\ \text { 6-PGT } & \text { 6-Phospho-gluconate; } \\ \text { Ru5P } & \text { ribulose 5-phosphate } \\ \text { R5P } & \text { ribose 5-phosphate } \\ \text { X5P } & \text { xylulose 5-phosphate } \\ \text { S7P } & \text { sedoheptulose 7-phosphate } \\ \text { GA3P } & \text { glyceraldehyde 3-phosphate } \\ \text { E4P } & \text { erythrose 4-phosphate; } \\ \text { DAHP } & \text { 3-deoxy-d-arobino-heptulosonate 7-phosphate; } \\ \text { DHS } & \text { 3-dehydroshikimate; } \\ \text { DHQ } & \text { 3-dehydroquinate } \\ \text { SHIK } & \text { shikimate } \\ \text { S3P } & \text { shikimate 3-phosphate } \\ \text { NADP } & \text { oxidized nicotinamide adenine dinucleotide phosphate } \\ \text { NADPH } & \text { reduced nicotinamide adenine dinucleotide phosphate; } \\ \text { ANTA } & \text { anthranilate } \\ \text { CHA } & \text { chorismate } \\ \text { I3GP } & \text { indole 3-glycerolphosphate } \\ \text { Ser } & \text { serine } \\ \text { Trp } & \text { tryptophan } \\ \text { Phe } & \text { phenylalanine } \\ \text { Tyr } & \text { tyrosine } \\ & \end{array}$

\section{References}

1. Hermann, T. Industrial production of amino acids by coryneform bacteria. J. Biotechnol. 2003, 104, $155-172$. [CrossRef]

2. Ikeda, M.; Nakagawa, S. The Corynebacterium glutamicum genome: Features and impacts on biotechnological processes. Appl. Microbiol. Biotechnol. 2003, 62, 99-109. [CrossRef]

3. Kirchner, O.; Tauch, A. Tools for genetic engineering in the amino acid-producing bacterium Corynebacterium glutamicum. J. Biotechnol. 2003, 104, 287-299. [CrossRef]

4. Leuchtenberger, W. Amino Acids-Technical Production and Use. In Biotechnology: Products of Primary Metabolism; Rehm, H.-J., Reed, G., Eds.; Verlagsgesellschaft mbH: Weinheim, Germany, 1996; Chapter 14a; pp. 465-502. 
5. Leuchtenberger, W.; Huthmacher, K.; Drauz, K. Biotechnological production of amino acids and derivatives: Current status and prospects. Appl. Microbiol. Biotechnol. 2005, 69, 1-8. [CrossRef]

6. Ikeda, M. Towards bacterial strains overproducing L-tryptophan and other aromatics by metabolic engineering. Appl. Microbiol. Biotechnol. 2006, 69, 615-626. [CrossRef]

7. Sanchez, S.; Demain, A.L. Microbial primary metabolites: Biosynthesis and perspectives. In Encyclopedia of Industrial Biotechnology: Bioprocess, Bioseparation, and Cell Technology; Flickinger, M.C., Ed.; John Wiley \& Sons, Inc.: Hoboken, NJ, USA, 2009; pp. 1-16.

8. Pontrelli, S.; Chiu, T.Y.; Lan, E.I.; Chen, F.Y.H.; Chang, P.; Liao, J. Escherichia coli as a host for metabolic engineering. Metab. Eng. 2018, 50, 16-46. [CrossRef]

9. Azuma, S.; Tsunekawa, H.; Okabe, M.; Okamoto, R.; Aiba, S. Hyper-production of L-trytophan via fermentation with crystallization. Appl. Microbiol. Biotechnol. 1993, 39, 471-476. [CrossRef]

10. Zhao, Z.J.; Zou, C.; Zhu, Y.X.; Dai, J.; Chen, S.; Wu, D.; Wu, J.; Chen, J. Development of L-tryptophan production strains by defined genetic modification in Escherichia coli. J. Ind. Microbiol. Biotechnol. 2011, 38, 1921-1929. [CrossRef] [PubMed]

11. Aiba, S.; Tsunekawa, H.; Imanaka, T. New approach to tryptophan production by Escherichia coli: Genetic manipulation of composite plasmids in vitro. Appl. Microbiol. Biotechnol. 1982, 43, 289-297.

12. Caligiuri, M.G.; Bauerle, R. Subunit Communication in the Anthranilate Synthase Complex from Salmonella typhimurium. Science 1991, 252, 1845-1848. [CrossRef]

13. Chan, E.C.; Tsai, H.L.; Chen, S.L.; Mou, D.G. Amplification of the tryptophan operon gene in Escherichia coli chromosome to increase L-tryptophan biosynthesis. Appl. Microbiol. Biotechnol. 1993, 40, 301-305. [CrossRef]

14. De, A.R.; Lara, A.R.; Hernández, V.; Hernández-Montalvo, V.; Gosset, G.; Bolívar, F.; Ramírez, O.T. Replacement of the glucose phosphotransferase transport system by galactose permease reduces acetate accumulation and improves process performance of Escherichia coli for recombinant protein production without impairment of growth rate. Metab. Eng. 2006, 8, 281-290.

15. Deutscher, J.; Aké, F.M.; Derkaoui, M.; Zébré, A.C.; Cao, T.N.; Bouraoui, H.; Kentache, T.; Mokhtari, A.; Milohanic, E.; Joyet, P. The bacterial phosphoenolpyruvate:Carbohydrate phosphotransferase system: Regulation by protein phosphorylation and phosphorylation-dependent protein-protein interactions. Microbiol. Mol. Biol. Rev. 2014, 78, 231-256. [CrossRef] [PubMed]

16. Sonja, K.B. Glucose Transport in Escherichia coli Mutant Strains with Defects in Sugar Transport Systems. J. Bacteriol. 2012, 194, 5897-5908.

17. Chen, Y.; Liu, Y.; Ding, D.; Cong, L.; Zhang, D. Rational design and analysis of an Escherichia coli strain for high-efficiency tryptophan production. J. Ind. Microbiol. Biotechnol. 2018, 45, 1-11. [CrossRef]

18. Wu, T.; Zhao, J.; Mao, X. Effect of PTS modifications on L-tryptophan production in Escherichia coli. Chin. J. Biotechnol. 2017, 33, 1877-1882.

19. Gu, P.; Kang, J.; Yang, F.; Wang, Q.; Liang, Q.; Qi, Q. The improved L-tryptophan production in recombinant Escherichia coli by expressing the polyhydroxybutyrate synthesis pathway. Appl. Microbiol. Biotechnol. 2013, 97, 4121-4127. [CrossRef]

20. Gu, P.; Fan, Y.; Kang, J.; Wang, Q.; Qi, Q. One-step of tryptophan attenuator inactivation and promoter swapping to improve the production of L-tryptophan in Escherichia coli. Microb. Cell. Fact. 2012, 11, 30. [CrossRef]

21. Snoep, J.L.; Arfman, N.; Yomano, L.P.; Fliege, R.K.; Conway, T.; Ingram, L.O. Reconstruction of glucose uptake and phosphorylation in a glucose-negative mutant of Escherichia coli by using Zymomonas mobilis genes encoding the glucose facilitator protein and glucokinase. J. Bacteriol. 1994, 176, 2133-2135. [CrossRef] [PubMed]

22. Liu, L.; Chen, S.; Wu, J. Phosphoenolpyruvate: Glucose phosphotransferase system modification increases the conversion rate during L-tryptophan production in Escherichia coli. J. Ind. Microbiol. Biotechnol. 2017, 44, 1-11. [CrossRef]

23. Singh, R.; White, D.; Demirel, Y.; Kelly, R.; Noll, K.; Blum, P. Uncoupling fermentative synthesis of molecular hydrogen from biomass formation in Thermotoga maritima. Appl. Environ. Microbiol. 2018, 84, e00998-18. [CrossRef]

24. Singh, R.; Tevatia, R.; White, D.; Demirel, Y.; Blum, P. Comparative kinetic modeling of growth and molecular hydrogen overproduction by engineered strains of Thermotoga maritima. Int. J. Hydrog. Energy. 2019, 44, 7125-7136. [CrossRef] 
25. Ongay, R. Tryptophan Biosynthesis by Genetically Engineered Escherichia coli Utilizing Different Carbon Sources; Texas A \& M University: College Station, TX, USA, 1994.

26. Siddiquee, K.A.Z.; Arauzo-Bravo, M.J.; Shimizu, K. Effect of a pyruvate kinase (pykF-gene) knockout mutation on the control of gene expression and metabolic fluxes in Escherichia coli. FEMS Microbiol. Lett. 2004, 235, 25-33. [CrossRef]

27. Al, Z.S.K.; Arauzobravo, M.J.; Shimizu, K. Metabolic flux analysis of pykF gene knockout Escherichia coli based on 13C-labeling experiments together with measurements of enzyme activities and intracellular metabolite concentrations. Appl. Microbiol. Biotechnol. 2004, 63, 407-417.

28. Kedar, P.; Colah, R.; Shimizu, K. Proteomic investigation on the gene knockout Escherichia coli for aromatic amino acid production. Enzyme Microb. Tech. 2007, 41, 455-465. [CrossRef]

29. Niersbach, M.; Kreuzaler, F.; Geerse, R.H.; Postma, W.; Hirsch, H.J. Cloning and nucleotide sequence of the Escherichia coli K-12 ppsA gene, encoding PEP synthase. Mol. Gen. Genet. 1992, 231, 332-336. [PubMed]

30. Liao, J.C.; Chao, Y.P.; Patnaik, R. Alteration of the biochemical valves in the central metabolism of Escherichia coli. Ann. NY Acad. Sci. 1994, 745, 21-34. [CrossRef] [PubMed]

31. Wang, J.; Zhang, T.; Yu, J.L.; Xu, Q.S.; Guo, C.J.; Huang, Y.W. Modification of the central metabolism of E. coli and its effect on tryptophan yield. Chin. Med. Biotechnol. 2008, 3, 93-97.

32. Tan, Z.; Zhu, X.; Chen, J.; Li, Q.; Zhang, X. Activating phosphoenolpyruvate carboxylase and phosphoenolpyruvate carboxykinase in combination for improvement of succinate production. Appl. Environ. Microb. 2013, 79, 4838-4844. [CrossRef]

33. Kikuchi, Y.; Tsujimoto, K.; Kurahashi, O. Mutational analysis of the feedback sites of phenylalanine-sensitive 3-deoxy-D-arabino-heptulosonate-7-phosphate synthase of Escherichia coli. Appl. Environ. Microb. 1997, 63, 761-762.

34. Bongaerts, J.; Krämer, M.; Müller, U.; Raeven, L.; Wubbolts, M. Metabolic Engineering for Microbial Production of Aromatic Amino Acids and Derived Compounds. Metab. Eng. 2001, 3, 289-300. [CrossRef] [PubMed]

35. Jossek, R.; Bongaerts, J.; Sprenger, G.A. Characterization of a new feedback-resistant 3-deoxy-d-arabinoheptulosonate 7-phosphate synthase AroF of Escherichia coli. FEMS Microbiol. Lett. 2001, 202, 145-148. [CrossRef]

36. Balderashernández, V.E.; Sabidoramos, A.; Silva, P.; Cabreravalladares, N.; Hernándezchávez, G.; Báezviveros, J.L.; Martínez, A.; Bolívar, F.; Gosset, G. Metabolic engineering for improving anthranilate synthesis from glucose in Escherichia coli. Microb. Cell. Fact. 2009, 8, 1-12.

37. Li, J.X.; Guo, C.J.; Liu, Y.; Lin, W.P.; Zhang, X.M.; Xu, Q.S. Cloning and expression of trpED encoding ANTA synthase Escherichia coli. Lett. Biotech. 2007, 18, 183-185.

38. Engelberg-Kulka, H.; Amiel, A.; Miller, C.; Schoulaker-Schwarz, R. Studies on the involvement of the UGA readthrough process in the mechanism of attenuation of the tryptophan operon of Escherichia coli. Mol. Gen. Genet. 1982, 188, 156-160. [CrossRef] [PubMed]

39. Tobey, K.L.; Grant, G.A. The nucleotide sequence of the serA gene of Escherichia coli and the amino acid sequence of the encoded protein, D-3-phosphoglycerate dehydrogenase. J. Biol. Chem. 1986, 261, 12179-12183.

40. Dodge, T.C.; Gerstner, J.M. Optimization of the glucose feed rate profile for the production of tryptophan from recombinant E coli. J. Chem. Technol. Biot. 2002, 77, 1238-1245. [CrossRef]

41. Liu, D.X.; Fan, C.S.; Tao, J.H.; Liang, G.X.; Gao, S.E.; Wang, H.J.; Li, X.; Song, D.X. Integration of E.coli aroG-phe $A$ tandem genes into Corynebacterium glutamicum tyr $A$ locus and its effect on L-phenylalanine biosynthesis. World J. Gastroenterol. 2004, 10, 3683-3687. [CrossRef]

42. Li, G.; Young, K.D. A new suite of tnaA mutants suggests that Escherichia coli tryptophanase is regulated by intracellular sequestration and by occlusion of its active site. BMC Microbiol. 2015, 15, 1-17. [CrossRef]

43. Marínsanguino, A.; Torres, N.V. Optimization of tryptophan production in bacteria. Design of a strategy for genetic manipulation of the tryptophan operon for tryptophan flux maximization. Biotechnol. Progr. 2000, 16, 133-145. [CrossRef]

44. Zhao, Z.J.; Chen, S.; Wu, D.; Wu, J.; Chen, J. Effect of gene knockouts of L-tryptophan uptake system on the production of L-tryptophan in Escherichia coli. Process Biochem. 2012, 47, 340-344. [CrossRef]

45. Gu, P.; Fan, Y.; Li, F.; Liang, Q.; Qi, Q. Knocking out analysis of tryptophan permeases in Escherichia coli for improving L-tryptophan production. Appl. Microbiol. Biotechnol. 2013, 97, 6677-6683. [CrossRef] 
46. Liu, R.; Liang, L.; Chen, K.; Ma, J.; Jiang, M.; Wei, P.; Ouyang, P. Fermentation of xylose to succinate by enhancement of ATP supply in metabolically engineered Escherichia coli. Appl. Microbiol. Biotechnol. 2012, 94, 959-968. [CrossRef]

47. Jing, L.I.; Shi, B.C.; Wang, C.Y.; Zhao, Z.J.; Shi, J.P. Effect of engineering of L-tryptophan transport system on L-tryptophan production in Escherichia coli. Sci. Technol. Food Indus. 2017, 15.

48. Wang, J.; Cheng, L.K.; Wang, J.; Liu, Q.; Shen, T.; Chen, N. Genetic engineering of Escherichia coli to enhance production of L-tryptophan. Appl. Microbiol. Biotechnol. 2013, 97, 7587-7596. [CrossRef]

49. Liu, L.; Duan, X.; Wu, J. L-Tryptophan Production in Escherichia coli Improved by Weakening the Pta-AckA Pathway. PLoS ONE 2016. [CrossRef]

50. Suárez, D.C.; Kilikian, B.V. Acetic acid accumulation in aerobic growth of recombinant Escherichia coli. Process Biochem. 2000, 35, 1051-1055. [CrossRef]

51. Phue, J.N.; Sang, J.L.; Kaufman, J.B.; Negrete, A.; Shiloach, J. Acetate accumulation through alternative metabolic pathways in ackA. Biotechnol. Lett. 2010, 32, 1897-1903. [CrossRef]

52. Mai, L.; Shanjing, Y.; Kazuyuki, S. Effect of poxB gene knockout on metabolism in Escherichia coli based on growth characteristics and enzyme activities. World J. Microb. Biot. 2007, 23, 573-580.

53. Kakuda, H.; Hosono, K.; Shiroishi, K.; Ichihara, S. Identification and characterization of the ackA (acetate kinase A)-pta (phosphotransacetylase) operon and complementation analysis of acetate utilization by an ackA-pta deletion mutant of Escherichia coli. J. Biochem. 1994, 116, 916-922. [CrossRef]

54. Zhao, C.; Cheng, L.K.; Wang, J.; Shen, Z.; Chen, N. Impact of deletion of the genes encoding acetate kinase on production of L-tryptophan by Escherichia coli. Ann. Microbiol. 2016, 66, 1-9. [CrossRef]

55. Klein, A.H.; Shulla, A.; Reimann, S.A.; Keating, D.H.; Wolfe, A.J. The Intracellular Concentration of Acetyl Phosphate in Escherichia coli Is Sufficient for Direct Phosphorylation of Two-Component Response Regulators. J. Bacteriol. 2007, 189, 5574-5581. [CrossRef]

56. Chang, D.E.; Shin, S.; Rhee, J.S.; Pan, J.G. Acetate metabolism in a pta mutant of Escherichia coli W3110: Importance of maintaining acetyl coenzyme A flux for growth and survival. J. Bacteriol. 1999, 181, 6656-6663. [PubMed]

57. Mccleary, W.R.; Stock, J.B. Acetyl phosphate and the activation of two-component response regulators. J. Biol. Chem. 1994, 269, 31567-31572.

58. Tyo, K.E.; Fischer, C.R.; Simeon, F.; Stephanopoulos, G. Analysis of polyhydroxybutyrate flux limitations by systematic genetic and metabolic perturbations. Metab. Eng. 2010, 12, 187-195. [CrossRef]

59. Gottesman, S. Bacterial regulation: Global regulatory networks. Annu. Rev. Genet. 1984, 18, 415-441. [CrossRef] [PubMed]

60. Schmidm, J.W.; Mauch, K.; Reuss, M.; Gilles, E.D.; Kremling, A. Metabolic design based on a coupled gene expression-metabolic network model of tryptophan production in Escherichia coli. Metab. Eng. 2004, 6, 364-377. [CrossRef]

61. Ramseier, T.M.; Bledig, S.; Michotey, V.; Feghali, R.; Saier, M.H.J. The global regulatory protein FruR modulates the direction of carbon flow in Escherichia coli. Mol. Microbiol. 1995, 16, 1157-1169. [CrossRef]

62. Ow, S.W.; Lee, M.Y.; Nissom, P.M.; Philp, R.; Oh, K.W.; Yap, G.S. Inactivating FruR global regulator in plasmid-bearing Escherichia coli alters metabolic gene expression and improves growth rate. J. Biotechnol. 2007, 131, 261-269. [CrossRef] [PubMed]

63. Yao, R.; Kurata, H.; Shimizu, K. Effect of cra gene mutation on the metabolism of Escherichia coli for a mixture of multiple carbon sources. Adv. Biosci. Biotechnol. 2013,4,477-486. [CrossRef]

64. Liu, L.; Duan, X.; Wu, J. Modulating the direction of carbon flow in Escherichia coli to improve L-tryptophan production by inactivating the global regulator FruR. J. Biotechnol. 2016, 231, 141-148. [CrossRef] [PubMed]

65. Sabnis, N.A.; Yang, H.; Romeo, T. Pleiotropic regulation of central carbohydrate metabolism in Escherichia coli via the gene csrA. J. Biol. Chem. 1995, 270, 29096-29104. [CrossRef]

66. Lijun, L.U.; Bin, Z.; Hong, Z.; Xinyao, L.U.; Fang, H.; Jian, S. Improved production of L-tryptophan in Escherichia coli with csrB and tktA overexpression. Chin. J. Appl. Environ. Biol. 2015, 21, 647-651.

67. Wang, J.G.; Fan, C.S.; Wu, Y.Q.; Jin, R.L.; Liu, D.X.; Shang, L.; Jiang, P.H. Regulation of aroP expression by tyrR gene in Escherichia coli. Acta Bioch. Bioph. Sin. 2003, 35, 993-997.

68. Shang, L.; Fan, C.S.; Jin, R.L.; Liu, D.X.; Wang, J.G.; Yin, J.; Song, D.X. Knockout of tyrR gene in Escherichia coli and its effects on the phenylalanine biosynthesis. Acta Bioch. Et. Bioph. Sin. 2003, 35, 728-733. 
69. Tripet, B.P.; Goel, A.; Copie, V. Internal dynamics of the tryptophan repressor (TrpR) and two functionally distinct TrpR variants, L75F-TrpR and A77V-TrpR, in their L-Trp-bound forms. Biochemistry 2011, 50, 5140-5153. [CrossRef]

70. Henkin, T.M.; Yanofsky, C. Regulation by transcription attenuation in bacteria: How RNA provides instructions for transcription termination/antitermination decisions. Bioessays 2002, 24, 700-707. [CrossRef]

71. Niu, H.; Li, R.; Liang, Q.; Qi, Q.; Li, Q.; Gu, P. Metabolic engineering for improving l-tryptophan production in Escherichia coli. J. Indus. Microbiol. Biotechnol. 2019, 46, 55-65. [CrossRef]

72. Cheng, L.K.; Wang, J.; Xu, Q.Y.; Xie, X.X.; Zhang, Y.J.; Zhao, C.G.; Chen, N. Effect of feeding strategy on L-tryptophan production by recombinant Escherichia coli. Ann. Microbiol. 2012, 62, 1625-1634. [CrossRef]

73. Luo, W.; Huang, J.; Zhu, X.C.; Huang, L.; Cai, J.; Xu, Z.N. Enhanced Production of L-Tryptophan with Glucose Feeding and Surfactant Addition and Related Metabolic Flux Redistribution in the Recombinant Escherichia coli. Food Sci. Biotechnol. 2013, 22, 207-214. [CrossRef]

74. Cheng, L.K.; Huang, J.; Qin, Y.F.; Xu, Q.Y.; Xie, X.X.; Wen, T.Y.; Chen, N. Effect of the byproduct-acetic acid on L-tryptophan fermentation. Microbiol. Chin. 2010, 37, 166-173.

75. Zou, C.; Chen, S.; Zhao, Z.J.; Lei, W.; Feng, L.; Wu, D.; Jian, C.; Wu, J. Optimization of L-tryptophan fermentation conditions from recombinant Escherichia coli. Ind. Microbiol. 2012, 42, 25-29.

76. Cheng, L.K.; Wang, J.; Xu, Q.Y.; Zhao, C.G.; Shen, Z.Q.; Xie, X.X.; Chen, N. Strategy for pH control and pH feedback-controlled substrate feeding for high-level production of L-tryptophan by Escherichia coli. World J. Microbiol. Biotechnol. 2013, 29, 883-890. [CrossRef] [PubMed]

77. Zhao, C.G.; Xie, X.X.; Cheng, L.K.; Qing-Yang, X.U. Effect of Temperature on the Process of Escherichia coli L-Tryptophan Fermentation. Lett. Biotechnol. 2009, 12, A88.

78. Chen, L.; Zeng, A.P. Rational design and metabolic analysis of Escherichia coli for effective production of L-tryptophan at high concentration. Appl. Microbiol. Biotechnol. 2017, 101, 59-568. [CrossRef] [PubMed]

79. Sadeghiyan-Rizi, T.; Fooladi, J.; Sadrai, S. Preliminary Study on Cost-Effective L-Tryptophan Production from Indole and L-Serine by E. Coli Cells. Avicenna. J. Med. Biotechnol. 2016, 8, 188-192.

80. Lu, J.; Tang, J.; Liu, Y.; Zhu, X.; Zhang, T.; Zhang, X. Combinatorial modulation of galP and glk gene expression for improved alternative glucose utilization. Appl. Microbiol. Biotechnol. 2012, 93, 2455-2462. [CrossRef] [PubMed]

81. Perrenoud, A.; Sauer, U. Impact of global transcriptional regulation by ArcA, ArcB, Cra, Crp, Cya, Fnr, and Mlc on glucose catabolism in Escherichia coli. J. Bacteriol. 2005, 187, 3171-3179. [CrossRef]

82. Prüss, B.M.; Campbell, J.W.; Van, T.D.; Zhu, C.; Kogan, Y.; Matsumura, P. FlhD/FlhC is a regulator of anaerobic respiration and the Entner-Doudoroff pathway through induction of the methyl-accepting chemotaxis protein Aer. J. Bacteriol. 2003, 185, 534-543. [CrossRef] 